\title{
Thyroid Suppressibility: Follow-up for Two Years after Antithyroid Treatment
}

\author{
R. C. LOWRY, DAPHNE LOWE, D. R. HADDEN, D. A. D. MONTGOMERY, J. A. WEAVER
}

British Medical fournal, 1971, 2, 19-22

\begin{abstract}
Summary
In hyperthyroidism suppression and non-suppression of early radioiodine neck uptake by exogenous thyroid hormone after a course of antithyroid drugs does not indicate clearly those patients who will eventually relapse or have a remission. Sixty-four hyperthyroid patients have been followed up for two years after an 18 to 24 months' course of carbimazole. Twenty-eight patients had suppressed at the end of the carbimazole course and 20 of these remained in remission for two years, and 36 were non-suppressed and 21 of these relapsed.
\end{abstract}

Patients with the highest neck uptakes relapsed soonest after stopping treatment. Pronounced rebound occurred in neck uptakes at one month after stopping treatment, both in patients who relapsed and in those who remained in remission. By one year after stopping treatment those who remained in remission had shown a further fall in early neck uptake. In two patients who relapsed after exposure to stressful events no change in 20-minute radioiodine neck uptakes was found in relation to the supposed stress.

\section{Introduction}

The observation that the administration of thyroid hormones did not suppress thyroid activity in patients with hyperthyroidism was made by Werner et al. (1952). Independently, Morgans et al. (1952) reported that patients rendered euthyroid by previous medical or surgical treatment had returned to normal suppression by thyroid hormone. Since then many studies have confirmed "non-suppressibility" of thyroid activity in hyperthyroidism and the administration of either thyroxine ( $\mathrm{T}-4)$ or triiodothyronine ( $\mathrm{T}-3)$ in conjunction with radioiodine uptake studies has been used to clarify difficulties in the diagnosis of hyperthyroidism.

The "suppression" test has also been used to predict the outcome of medical treatment with antithyroid drugs. It was originally suggested by Cassidy and VanderLaan (1960) that patients who showed suppression at the end of a course of antithyroid drugs remained in remission, and this was confirmed in several studies by Alexander et al. (1967, 1968, 1969). The accuracy of this prediction was thought to be good $-81 \%$ correct in the series of Cassidy and VanderLaan, and $92 \%$ correct for the studies of Alexander et al. The overall accuracy of prediction is also influenced by the outcome of the non-suppressed patients. If non-suppression is usually followed by relapse, as has been suggested by Alexander et al., the general division into the two groups suppressed and non-suppressed would have useful clinical Sir George E. Clark Metabolic Unit, Royal Victoria Hospital, Belfast
BT 12 6BA

R. C. LOWRY, M.B., M.R.C.P., former Senior Registrar (Present appointment: Consultant Physician, Belfast City Hospital)

DAPHNE LOWE, M.B., M.R.C.P.ED., Medical Research Council Assistant DAPHNE LOWE, M.B., M.R.C.P.ED., Medical Research Co
D. R. HADDEN, M.D., F.R.C.P.ED., Consultant Physician

D. R. HADDEN, M.D., F.R.C.P.ED., Consultant Physician
D. A. D. MONTGOMERY, M.D., F.R.C.P., Physician-in-charge

J. A. WEAVER, M.D., F.R.C.P., Consultant Physician value. A subsequent study by Hales et al. (1969), however, reported that only $50 \%$ of non-suppressed patients relapsed. It is therefore not clear that a fundamental distinction exists between patients who show "suppression" and those who do not at the end of a course of antithyroid drugs. Further insight into the status of both groups might be obtained by serial radioiodine studies in the period after cessation of antithyroid drugs. The present study reports a follow-up of patients after a course of antithyroid drug treatment and compares the pattern of radioiodine neck uptakes in suppressed and non-suppressed patients over a period of two years from cessation of treatment.

\section{Patients and Methods}

Sixty-four hyperthyroid patients treated with carbimazole for a relatively uniform period of between 18 and 24 months were studied. They were first seen in 1965-6. Their original selection for antithyroid drug treatment rather than radioiodine or surgery was based primarily on the presence of a small goitre (less than 50-60 g estimated weight) and absence of nodularity of the gland, and also by exclusion of patients over 60 years of age.

Treatment initially was with carbimazole $45-60 \mathrm{mg}$ daily, with the addition of $\mathrm{L}$-thyroxine sodium $0.1 \mathrm{mg} /$ day after 4 to 10 weeks. The dose of these drugs was gradually altered throughout the course of treatment, on the basis of clinical response and biochemical criteria, by decreasing the carbimazole and increasing the L-thyroxine. Finally, at 18 to 24 months the dose of carbimazole was $10-20 \mathrm{mg}$ daily and of L-thyroxine $0.3 \mathrm{mg}$ daily. At this time, while still on treatment with both drugs, a 20-minute neck uptake after the intravenous administration of ${ }^{132} \mathrm{I}$ was determined. The 20-minute uptake values were corrected for background by the mathematical formula of Alexander et al. (1967). A 20-minute neck uptake of less than $8 \%$ of the dose of radioiodine has been taken as indicating suppression. All treatment, both with carbimazole and with thyroxine, was then stopped and this test was repeated after $1,3,5,12$, and 24 months. In addition, proteinbound iodine and $\mathrm{T}-3$ red cell uptake tests were repeated at each visit.

During the follow-up period of two years after cessation of antithyroid drugs relapse was regarded as established only when there was unequivocal agreement between the laboratory tests (protein-bound iodine and T-3 red cell uptake) and clinical opinion.

\section{Results}

The findings with regard to suppression or non-suppression at the end of the course of antithyroid drug treatment are:

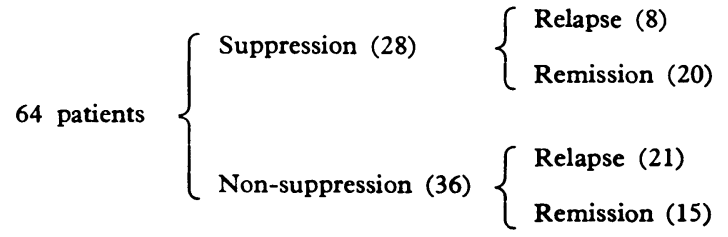

Total relapse $=29 . \quad$ Total remission $=35$. 
Of the 64 patients, 28 had a radioiodine 20-minute neck uptake which suppressed below $8 \%$ at the end of the course of treatment. Suppression at this point in time was clearly associated with a good prognosis for remission as judged at the subsequent two-year follow-up. Thus of the 28 patients who were suppressed, 20 remained in remission, and prediction of remission within this group would be correct about three times in four. Non-suppression is less accurately associated with relapse. Of 36 patients who did not suppress, 21 relapsed but 15 remained in remission during the two-year follow-up. Prediction within this group would therefore be correct about six times in 10. Thus of 35 patients in remission two years after stopping therapy, only 20 had previously "suppressed."

The progressive pattern of 20-minute radioiodine neck uptakes for the two groups-remission and relapse-over the period of the first year of follow-up is shown in Fig. 1. It can be seen that as groups the neck uptakes are different at all the intervals. A rebound phenomenon in neck uptake of a

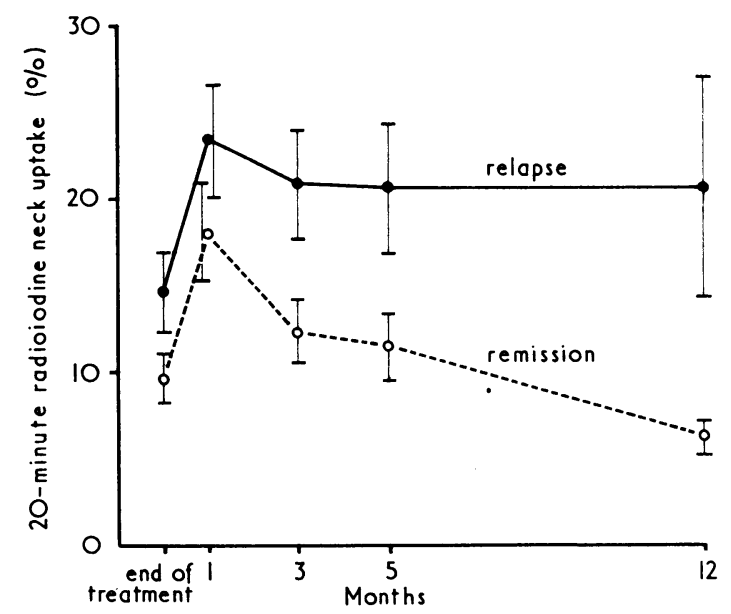

FIG. 1-Pattern of 20-minute neck uptakes over the first year after cessation of treatment (mean \pm S.D.).

reasonably similar pattern occurred in both groups at one month after cessation of therapy. Six of the 35 patients who remained in long-term remission had temporary increases in their serum protein-bound iodine levels into the thyrotoxic range (between 8 and $10 \mu \mathrm{g} / 100 \mathrm{ml}$ ) at the one-month review coinciding with the peak of this rebound phenomena, showing that factors other than simple iodine deficiency influence this phenomenon. In 10 patients thyroid clearance was estimated by the methods of Koutras and Sfontouris (1966) at the peak of the rebound phenomenon and three months later. When the "net clearance" for 20 minutes to two hours was calculated as a percentage of the "unidirectional clearance" 2 to 20 minutes, no significant change was found-mean at rebound $73.2 \%$, mean three months later $76.1 \%$.

In those patients who remained in remission the ${ }^{132} \mathbf{I} 20$ minute neck uptake figures at one year after stopping antithyroid drugs (Fig. 1) are lower than at the end of treatment, suggesting that it takes a long time-6 to 12 months-to achieve equilibrium, whether this be through pituitary-thyroid homoeostasis or iodine pool repletion.

In Fig. 2 the patients are divided into the more detailed groups: A, non-suppression $\rightarrow$ relapse (21 patients); B, nonsuppression $\rightarrow$ remission (15 patients); C, suppression $\rightarrow$ relapse (8 patients); and $\mathrm{D}$, suppression $\rightarrow$ remission (20 patients). Group A shows constant high neck uptakes throughout the follow-up period. Group B shows a gradual fall in neck uptakes-by definition all this group had 20-minute neck uptakes in excess of $8 \%$ at the time of stopping antithyroid drugs, but one year later only 5 of the 15 patients still had

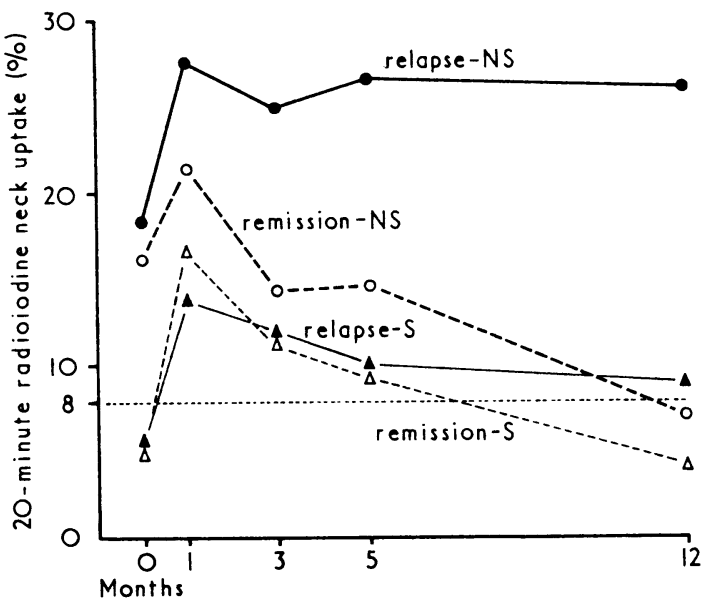

FIG. 2-Serial neck uptakes (mean values for each group). $A$, relapse-NS (non-suppressed); B, remission-NS (nonsuppressed); C, relapse-S (suppressed); D, remission-S (suppressed).

uptakes in excess of $8 \%$. The suppression with relapse group (group C) is characterized by relatively little alteration in their neck uptakes throughout the period of study, and even at the time of relapse their neck uptakes are relatively low.

Patients with the highest radioiodine uptakes relapsed very quickly. For those who relapsed within one month the mean 20-minute neck uptake at the time of stopping carbimazole

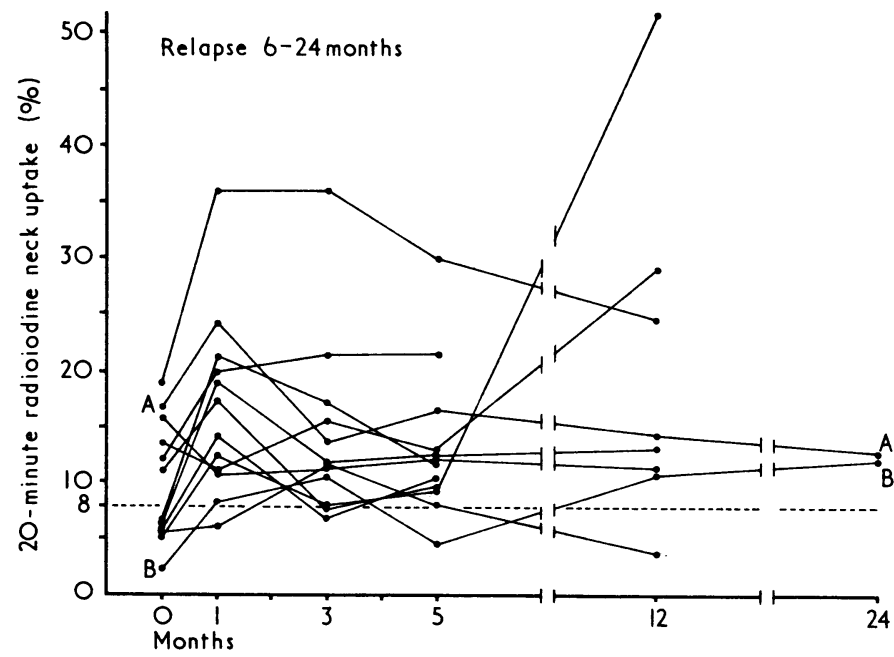

FIG. 3-Individual pattern of neck uptakes in patients who relapsed 6 to 24 months after stopping carbimazole, charted until the time of relapse. Patients $\mathbf{A}$ and $\mathbf{B}$ exposed to stressful events.

was $25 \%$, and, furthermore, in this group none had been suppressed. The association between highest neck uptakes and speed of relapse has already been reported by Cassidy and VanderLaan (1960). Patients who relapsed later showed no further characteristic, except that a significant proportion of late relapses came from the suppressed group (relapse at one to five months, only two out of nine were suppressed; relapse at 6 to 24 months, 6 out of 13 had been suppressed). The individual patterns of neck uptakes in the patients who relapsed in 6 to 24 months are shown in Fig. 3.

Alexander et al. (1968) reported an association between stressful events and relapse. Two of our patients with late relapse at 20 to 24 months were also exposed to such events (in one the deaths of husband and sister within one month; and in another patient several months' close contact with civil riots). From a clinical point of view both these histories seemed relevant to the occurrence of thyrotoxic relapse, but 
the graph of their neck uptakes (Fig. 3) shows no change at the time of these events.

Of the patients who remained euthyroid (groups $B$ and D) for two years, 20 (10 originally suppressed and 10 originally non-suppressed) had repeat suppression tests carried out utilizing $100 \mu \mathrm{g}$ of T-3 daily for one week (Fig. 4). All the patients originally suppressed had 20-minute neck uptakes less than $8 \%$ but three of the original non-suppressed group

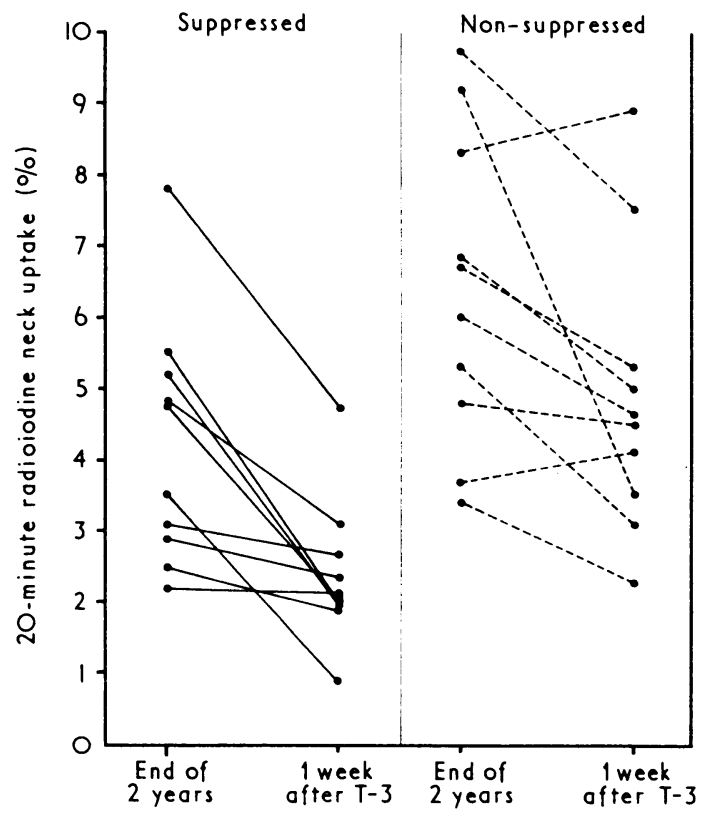
FIG. 4-Repeat suppression tests with $T-3(100 \mu \mathrm{g}$ daily for suppressed and 10 patients originally non-suppressed).

had uptakes in excess of $8 \%$ in this repeat test. The mean initial uptakes in the original suppressed group was $4.3 \%$ $\pm 0.43 \%$ and after one week's resuppression fell to $2.4 \%$ $\pm 0.30 \%$. In the original non-suppressed patients the change was from $6.4 \% \pm 0.65 \%$ to $4.9 \% \pm 0.60 \%$. Paired $t$ test between the differences was not significant $(P>0 \cdot 6)$.

\section{Discussion}

Thyroid suppression during and after antithyroid drug treatment has been extensively investigated. Reversion to normal suppression by L-thyroxine sodium after antithyroid drug treatment and after thyroidectomy was first described by Morgans et al. (1952), though only a few cases were studied. Werner and Spooner (1955) introduced the T-3 suppression test, and Werner (1956) utilized this test to study hyperthyroid patients who were euthyroid after treatment with radioactive iodine or surgery. In most patients treated with ${ }^{131} I$ the thyroid could not be suppressed up to five years later (ratio of abnormal to normal responses 5:1). After surgery normal suppression was evident within one year (ratio of abnormal to normal responses 1:2). Cassidy and VanderLaan (1960) studied 29 patients who had been treated with antithyroid drugs. One year after cessation of treatment 18 were well and their original suppression tests had yielded a mean 24 -hour ${ }^{131}$ I neck uptake of $28 \%$ compared with $66 \%$ in the 11 who had relapsed in the interval.

Stanley and Astwood (1948) had shown that the measurement of thyroid uptake of an iodine isotope 10 minutes after intravenous injection was not altered by previous administration of thiouracil or carbimazole group of drugs. The rate of iodide accumulation during this early phase is related to the iodide trapping mechanism, which is blocked by drugs such as perchlorate but not by the usual antithyroid drugs that affect the later stage of thyroid hormone synthesis. Alexander et al. (1966) utilized early uptake studies to estimate thyroid suppression before treatment and at frequent intervals during treatment with carbimazole and T-3. Neck counting was carried out at 20 minutes after the intravenous administration of the isotope ${ }^{132} \mathrm{I}$.

Twenty-six thyrotoxic patients were studied during longterm treatment with carbimazole and T-3 (Alexander et al., 1967) - 17 developed suppression and none of these relapsed and nine did not show suppression and seven of these relapsed. It was further claimed that these groups could be separated after six months' antithyroid treatment. Alexander et al. also suggested that suppression could be a guide to the earlier management of some patients. Relapse-prone patients (non-suppressed) should be advised to have treatment by surgery or radioiodine as soon as they were recognized, perhaps after six months' treatment. Long-acting thyroid stimulator is also known to be lower in patients with small goitres, and it was therefore suggested that long-acting thyroid stimulator and non-suppression of thyroid activity in thyrotoxicosis might be related (Alexander and Harden, 1967). Chopra et al. (1970), however, failed to relate thyroid non-suppressibility with serum long-acting thyroid stimulator levels.

Hales et al. (1969) divided patients into three groups as opposed to the usual division in earlier studies of two groupssuppressed and non-suppressed. Their patients consisted of 11 out of 63 who became suppressible and 26 of the 63 who were non-suppressible, but, in addition, 16 of the 63 showed a pronounced decline in early neck uptakes on antithyroid drugs alone-that is, without the challenge of thyroid hormone administration. This latter group, who showed a "spontaneous" decline in early neck uptakes during antithyroid drug treatment, had a pronounced tendency to stay in remission$3.8 \%$ recurrence rate as opposed to $27.3 \%$ recurrence rate in those patients who suppressed only after the addition of thyroxine medication. It is not clear whether this separation into three groups instead of two provides any more reliable information with regard to prognosis.

The present study does not support the concept that useful prediction can be made at the end of a course of antithyroid drugs by separating patients into distinct groups on the basis of suppression and non-suppression. Non-suppressed patients who have the highest neck uptake relapsed relatively quickly, but within this same group of non-suppressed patients a considerable proportion (15 out of 36 ) after the initial rebound in neck uptakes showed a slow decline in thyroid uptake which occurred over a period of many months. It is apparent that neck uptake studies are diagnostically misleading for long periods after cessation of antithyroid drugs. Studies by Harden et al. (1966) suggested that iodine deficiency may play some part in the rebound pattern of thyroid uptake in the period after cessation of treatment.

The patients who were suppressed and relapsed late after cessation of antithyroid drugs are particularly interesting in the sequential pattern of their neck uptakes. The neck uptakes throughout the long period of follow-up showed no appreciable change, and at the time when relapse occurred no pronounced increment in neck uptake was found. This suggests the possibility that intrathyroidal mechanisms may alter at the time of relapse rather than any change in neck uptake or, alternatively, that these patients have a fixed upper limit to thyroid trapping which impedes their ability to relapse quickly.

We would like to acknowledge with thanks the help of Dr. T. K. Bell, Dr. R. Ferguson, Mr. J. Todd, and Sister K. Farrell, of the radioisotope department, Royal Victoria Hospital, Belfast, and also Miss $M$. Weller.

\section{References}

Alexander, W. D., and Harden, R. McG. (1967). In Symposium on Thyrotoxicosis, ed. W. J. Irvine, p. 99. Edinburgh, Livingstone.

Alexander, W. D., Harden, R. McG., and Shimmins, J. (1966). Lancet, 2, 1041 . 
Alexander, W. D., Harden, R. McG., Shimmins, J., McLarty, D., and McGill, P. (1967). Fournal of Endocrinology, 27, 1682.

Alexander, W. D., Harden, R. McG., and Shimmins, J. (1968). Lancet, 2 , 196.

Alexander, W. D., Harden, R. McG., McLarty, D., and Shimmins, J. (1969). Metabolism, 1, 58 .

Cassidy, C. E., and VanderLaan, W. P. (1960). New England fournal of Medicine, 262, 1228.

Chopra, I. J., Solomon, D. H., Johnson, D. E., Chopra, U., and Fisher, D. A. (1970). Fournal of Endocrinology, 30, 524

Hales, I., Stiel, J., Reeve, T., Heap, T., and Myhill, J. (1969). fournal of Endocrinology, 29, 998.
Harden, R. McG., Alexander, W. D., Koutras, D. A., Harrison, M. T., and Wayne, E. (1966). Fournal of Endocrinology, 26, 397.

Koutras, D. A., and Sfontouris, J. (1966). Fournal of Endocrinology, 35, 135 Morgans, M. E., Oldham, A. K., and Trotter, W. R. (1952). Fournal of Endocrinology, 8, 250.

Stanley, M. M., and Astwood, E. B. (1948). Endocrinology, 42, 107.

Werner, S. C. (1956), Fournal of Clinical Investigation, 35, 57 .

Werner, S. C., Hamilton, H., and Nemeth, M. (1952). Fournal of Endocrinology, 12, 1561.

Werner, S. C., and Spooner, M. (1955). Bulletin of the New York Academy of Sciences, 31, 137.

\section{Urinary Sodium and Potassium Excretion in Fasting Obese Subjects}

\section{J. RUNCIE}

\section{British Medical fournal, 1971, 2, 22-25}

\section{Summary}

Data are presented on the urinary excretion of sodium and potassium in $\mathbf{4 0}$ obese patients subjected to therapeutic starvation. Two patterns of sodium loss were observed: either a uniform low-level loss or a fluctuating loss leading in some cases to marked sodium depletion. In three patients the response was a combination of these two patterns.

\section{Introduction}

Therapeutic starvation as a significant mode of therapy for the obese patient dates from the observations of Bloom (1959), which were extended by Duncan et al. (1962), Drenick et al. (1964), and Thompson et al. (1966) and which established the validity of this form of treatment. Runcie and Thomson (1970) reviewed the hazards of therapeutic starvation and

University of Glasgow, Stobhill Hospital, Glasgow N.1

J. RUNCIE, M.B., M.R.C.P.GLASG., Lecturer in Materia Medica drew attention to a hitherto unrecognized danger, the spontaneous development of a renal leak of electrolytes (sodium and potassium), leading to hyponatraemic shock.

With acceptance of the principle of therapeutic starvation interest has become increasingly focused on the mechanisms and adaptive responses necessary to enable man to survive prolonged deprivation of food. Considerable advances have been made in some fields, such as the description by Cahill and his co-workers (Cahill et al., 1966; Felig et al., 1969; Owen et al., 1969) of many essential changes in protein metabolism in fasting.

The purpose of this communication is to present data on the urinary excretion of sodium and potassium in 40 obese patients who had undergone varying periods of therapeutic starvation and to consider the nature of this response and its role in the integrated, adaptive, renal response to starving.

\section{Methods}

The management of obese patients admitted to the wards of the University Department of Materia Medica for therapeutic starvation has been described previously (Thomson et al., 1966). The urine of all patients is collected continuously in

TABLE I-Urinary Sodium $(m E q / 24 h r)$

\begin{tabular}{|c|c|c|c|c|c|c|c|c|c|c|c|c|c|c|c|c|c|c|c|c|c|c|}
\hline \multirow{2}{*}{$\begin{array}{l}\text { Case } \\
\text { No. }\end{array}$} & \multirow{2}{*}{$\underset{\text { (years) }}{\text { Age }}$} & \multirow{2}{*}{ Sex } & \multicolumn{20}{|c|}{ Fast (Day) } \\
\hline & & & 1 & 2 & 3 & 4 & 5 & 6 & 7 & 8 & 9 & 10 & 11 & 12 & 13 & 14 & 15 & 16 & 17 & 18 & 19 & 20 \\
\hline 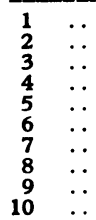 & $\begin{array}{l}14 \\
16 \\
28 \\
29 \\
31 \\
35 \\
48 \\
47 \\
52 \\
57\end{array}$ & $\begin{array}{l}\text { M. } \\
\text { F. } \\
\text { M. } \\
\text { F. } \\
\text { F. } \\
\text { F. } \\
\text { F. } \\
\text { M. } \\
\text { F. } \\
\text { F. }\end{array}$ & $\begin{array}{r}60 \\
109 \\
151 \\
93 \\
142 \\
43 \\
114 \\
174 \\
120 \\
141\end{array}$ & $\begin{array}{r}62 \\
98 \\
118 \\
65 \\
74 \\
55 \\
114 \\
165 \\
106 \\
52\end{array}$ & $\begin{array}{r}95 \\
90 \\
106 \\
42 \\
51 \\
70 \\
90 \\
102 \\
102\end{array}$ & $\begin{array}{r}61 \\
122 \\
94 \\
35 \\
73 \\
74 \\
43 \\
127 \\
68 \\
42\end{array}$ & $\begin{array}{r}25 \\
110 \\
63 \\
28 \\
47 \\
85 \\
16 \\
38 \\
48 \\
52\end{array}$ & $\begin{array}{r}11 \\
45 \\
59 \\
17 \\
27 \\
104 \\
32 \\
120 \\
40 \\
26\end{array}$ & $\begin{array}{l}1 \\
13 \\
15 \\
12 \\
11 \\
95 \\
32 \\
29 \\
75\end{array}$ & $\begin{array}{r}0 \\
0 \\
13 \\
40 \\
4 \\
77 \\
78 \\
18 \\
6\end{array}$ & $\begin{array}{r}2 \\
3 \\
14 \\
47 \\
4 \\
57 \\
94 \\
6 \\
21 \\
40\end{array}$ & $\begin{array}{r}1 \\
8 \\
11 \\
1 \\
31 \\
40 \\
13 \\
17 \\
51\end{array}$ & $\begin{array}{r}2 \\
3 \\
9 \\
2 \\
16 \\
36 \\
25 \\
9 \\
68\end{array}$ & $\begin{array}{r}3 \\
1 \\
15 \\
2 \\
77 \\
20 \\
40 \\
17 \\
101\end{array}$ & $\begin{array}{r}4 \\
0 \\
58 \\
1 \\
11 \\
29 \\
31 \\
17 \\
64\end{array}$ & $\begin{array}{c}5 \\
1 \\
14 \\
1 \\
15 \\
20 \\
30 \\
4 \\
30\end{array}$ & $\begin{array}{r}4 \\
2 \\
31 \\
44 \\
1 \\
31 \\
11 \\
30 \\
6 \\
30\end{array}$ & $\begin{array}{r}4 \\
1 \\
24 \\
32 \\
1 \\
19 \\
11 \\
31 \\
11 \\
13\end{array}$ & $\begin{array}{r}3 \\
0 \\
19 \\
31 \\
22 \\
24 \\
25 \\
35 \\
13 \\
4\end{array}$ & $\begin{array}{r}1 \\
1 \\
24 \\
36 \\
11 \\
9 \\
28 \\
21 \\
11 \\
3\end{array}$ & $\begin{array}{r}1 \\
1 \\
32 \\
32 \\
13 \\
18 \\
34 \\
14 \\
6 \\
3\end{array}$ & $\begin{array}{r}2 \\
11 \\
15 \\
32 \\
4 \\
30 \\
20 \\
13 \\
4 \\
1\end{array}$ \\
\hline
\end{tabular}

TABLE II-Urinary Sodium ( $m E q / 24 h r)$

\begin{tabular}{|c|c|c|c|c|c|c|c|c|c|c|c|c|c|c|c|c|c|c|c|c|c|c|c|}
\hline \multirow{2}{*}{$\begin{array}{l}\text { Case } \\
\text { No. }\end{array}$} & \multirow{2}{*}{$\begin{array}{c}\text { Age } \\
\text { (years) }\end{array}$} & \multirow{2}{*}{ Sex } & \multicolumn{21}{|c|}{ Fast (Day) } \\
\hline & & & 40 & 41 & 42 & 43 & 44 & 45 & 46 & 47 & 48 & 49 & 50 & 51 & 52 & 53 & 54 & 55 & 56 & 57 & 58 & 59 & 60 \\
\hline $\begin{array}{r}1 \ldots \\
2 \ldots \\
3 \ldots \\
4 \ldots \\
5 \ldots \\
6 \ldots \\
7 \ldots \\
9 . . . \\
10 . .\end{array}$ & $\begin{array}{l}14 \\
16 \\
28 \\
29 \\
31 \\
35 \\
48 \\
47 \\
52 \\
57\end{array}$ & $\begin{array}{l}\text { M. } \\
\text { F. } \\
\text { M. } \\
\text { F. } \\
\text { F. } \\
F . \\
F . \\
\text { M. } \\
\text { F. } \\
\text { F. }\end{array}$ & $\begin{array}{c}\text { Fas } \\
24 \\
5 \\
90 \\
109 \\
1 \\
37 \\
33 \\
9 \\
15\end{array}$ & $\begin{array}{r}\text { ended } \\
19 \\
6 \\
118 \\
52 \\
2 \\
60 \\
34 \\
7 \\
8\end{array}$ & $\begin{array}{c}\text { fter } 27 \\
11 \\
9 \\
106 \\
34 \\
3 \\
60 \\
50 \\
8 \\
3\end{array}$ & $\begin{array}{r}\text { days } \\
3 \\
8 \\
138 \\
4 \\
4 \\
82 \\
39 \\
8 \\
4\end{array}$ & $\begin{array}{r}8 \\
5 \\
134 \\
8 \\
11 \\
27 \\
\frac{10}{10} \\
1\end{array}$ & $\begin{array}{r}2 \\
4 \\
31 \\
17 \\
29 \\
39 \\
9 \\
3\end{array}$ & $\begin{array}{r}11 \\
4 \\
130 \\
28 \\
37 \\
43 \\
58 \\
6 \\
17\end{array}$ & $\begin{array}{r}16 \\
6 \\
261 \\
20 \\
25 \\
16 \\
47 \\
10 \\
8\end{array}$ & $\begin{array}{r}17 \\
6 \\
142 \\
18 \\
31 \\
5 \\
46 \\
8 \\
15\end{array}$ & $\begin{array}{r}8 \\
7 \\
34 \\
22 \\
42 \\
36 \\
50 \\
7 \\
17\end{array}$ & $\begin{array}{r}13 \\
6 \\
84 \\
12 \\
41 \\
22 \\
47 \\
4 \\
42\end{array}$ & $\begin{array}{l}\frac{29}{24} \\
15 \\
21 \\
50 \\
68 \\
14 \\
45\end{array}$ & $\begin{array}{l}\overline{2} \\
36 \\
11 \\
\text { Fast } \\
32 \\
91 \\
5 \\
55\end{array}$ & $\begin{array}{c}6 \\
6 \\
81 \\
14 \\
\text { ended } \\
24 \\
39 \\
10 \\
\end{array}$ & $\begin{array}{r}3 \\
4 \\
66 \\
8 \\
11 \\
30 \\
21\end{array}$ & $\begin{array}{r}11 \\
5 \\
142 \\
13 \\
43 \\
44\end{array}$ & $\begin{array}{r}12 \\
6 \\
52 \\
18 \\
20 \\
47 \\
7 \\
12\end{array}$ & $\begin{array}{r}17 \\
6 \\
44 \\
39 \\
48 \\
43 \\
6 \\
7\end{array}$ & $\begin{array}{r}14 \\
8 \\
44 \\
49 \\
41 \\
45 \\
11 \\
12\end{array}$ & $\begin{array}{r}16 \\
6 \\
125 \\
78 \\
28 \\
46 \\
7 \\
22\end{array}$ & $\begin{array}{r}18 \\
6 \\
45 \\
144 \\
61 \\
32 \\
7 \\
20\end{array}$ \\
\hline
\end{tabular}

